\title{
NARCISO SEM ESPELHO: A PUBLICAÇÃO BRASILEIRA DE MARKETING
}

\section{RESUMO}

Este artigo analisa a influência da publicação científica brasileira na área de marketing para a produção acadêmica no Brasil. A análise concerniu aos anos 1990, quando se observou 272 artigos publicados nos principais periódicos brasileiros de administração. As variáveis investigadas foram, por um lado, a temática, o número de autores e a filiação acadêmica dos autores dos artigos, e, por outro, o número total de citações por artigo, o número total de citações de periódicos, além do número de citações relativo a periódicos internacionais e brasileiros por artigo publicado. Após a análise de 5.883 citações bibliográficas, constata-se que a publicação científica brasileira na área de marketing não tem servido como uma referência para a produção acadêmica da própria área. Isso revela que, embora existam consideráveis referências sobre a realidade empírica empresarial brasileira no âmbito dos periódicos, os pesquisadores têm relegado tais referências como fontes de pesquisa.

\section{Francisco Giovanni David Vieira}

UEM

\begin{abstract}
The article analyzes the influence of the Brazilian scientific publication in the marketing area for the academic production of marketing in Brazil. A total of 272 articles published during the nineties in the main Brazilian journals were observed. The variables of investigation were the subject, number of authors, authors' academic institution, total number of citations, total number of citations from journals, besides the number of citations from international and Brazilian journals in each published article of that period. After the analysis of 5,883 bibliographical references, was verified that the Brazilian scientific publication in the marketing area has not been serving as a reference for the academic production of the area itself. This reveals that, although considerable references exist about the Brazilian managerial empiric reality in the ambit of the journals, the Brazilian scholars have been relegating such references as sources for their researches.
\end{abstract}

PALAVRAS-CHAVE Publicação científica, produção acadêmica, marketing, Brasil, periódicos brasileiros.

KEY WORDS Scientific publication, academic production, marketing, Brazil, Brazilian journals. 


\section{INTRODUÇÃO}

A publicação científica de marketing no Brasil nos anos 1990 foi veiculada, principalmente, por meio de três periódicos: Anais do Encontro Anual da Associação Nacional dos Programas de Pós-Graduação em Administração - Enanpad -; Revista de Administração RAUSP -, editada pela Universidade de São Paulo USP -; e Revista de Administração de Empresas - RAE -, editada pela Escola de Administração de Empresas da Fundação Getúlio Vargas - FGV-EAESP. Esses três periódicos são considerados como os mais significativos em função da regularidade de publicação e do longo período de tempo que têm de edição - RAE 41, RAUSP 36, e Anais do Enanpad 25 anos, respectivamente -, da representatividade acadêmica neles contida e, sobretudo, pelo fato de existirem poucos periódicos temáticos acadêmico-científicos no Brasil. Aqueles que existem, como a Revista de Estudos Organizacionais REO -, editada pela Universidade Estadual de Maringá - UEM -; a Revista Organizações e Sociedade - O\&S -, editada pela Universidade Federal da Bahia - UFBA -; e a Organizações Rurais e Agroindustriais - Revista de Administração da UFLA, editada pela Universidade Federal de Lavras - UFLA -, são circunscritos ou mais próximos à área de estudos organizacionais e ainda são relativamente novos. A Revista de Administração Contemporânea - RAC -, editada pela Anpad, por sua vez, é um periódico generalista na área de Administração de Empresas, mas que começou a ser editado apenas em 1997.

Tendo em vista, portanto, a relevância dos Anais do Enanpad, da RAUSP e da RAE, e considerando que entre suas diversas áreas temáticas está a de marketing, o presente artigo assume o pressuposto de que os trabalhos - artigos e ensaios - publicados nesses três periódicos refletem a produção acadêmica, bem como o esforço de pesquisa em marketing, realizado tanto no âmbito interno quanto externo dos cursos de pós-graduação em Administração no Brasil. Assim, compreendese que a publicação científica presente nos Anais do Enanpad, na RAUSP e na RAE na área de marketing vem a se caracterizar como uma referência fundamental do estado da arte em marketing no Brasil, seja do ponto de vista eminentemente teórico e conceitual que analisa, seja sob o aspecto empírico da atividade empresarial que documenta, registra e investiga.

Em que medida tal caráter da publicação científica na área de marketing no Brasil tem sido evidenciado? Há, de fato, o reconhecimento e o uso dessa publica- ção por parte dos pesquisadores dentro do processo de desenvolvimento de pesquisas em marketing no Brasil? Responder a essas perguntas foi o que buscou a pesquisa da qual este artigo é resultado.

No sentido de sua apresentação, o artigo faz uso de uma metáfora em relação a Narciso, um personagem da mitologia grega que admirava sua beleza nas águas de uma fonte que lhe serviam de espelho. O texto está dividido em quatro momentos: no primeiro, são assinalados aspectos gerais relativos à questão da produção acadêmica (o espelho); no segundo, é especificado o procedimento metodológico seguido para a realização dessa pesquisa (vendo o espelho); no terceiro, são apresentados os resultados de acordo com as variáveis usadas (as imagens no espelho); e, no quarto e último momento, são destacadas as principais conclusões da pesquisa (Narciso sem espelho).

\section{O ESPELHO: SOBRE A PRODUÇÃO E A PUBLICACÃO ACADÊMICAS NA ÁREA DE MARKETING}

Alguns estudos sobre aspectos relacionados à produção acadêmica no Brasil foram realizados nos anos 1990. Entretanto, eles estiveram voltados pioneiramente para a área de organizações, que é o caso daqueles realizados por Machado-da-Silva, Cunha e Amboni (1990), Bertero e Keinert (1994), Vergara e Carvalho (1995) e Bertero, Caldas e Wood Jr. (1998). Esses estudos, publicados no Brasil, pareciam refletir, à época, uma tendência mundial em se analisar a temática em organizações, inclusive do ponto de vista acadêmico, como indica a publicação do trabalho de Chanlat (1994).

Artigos como os de Niemi Jr. (1988), Burnett, Amason e Cunningham (1989) e Sherrell, Hair Jr. e Griffin (1989) chamaram a atenção no final dos anos 1980 para a necessidade de debates envolvendo aspectos acadêmicos de marketing. Todavia, após alguns anos, foi o artigo publicado por Powers, Swan e Patton (1998) que terminou por contemplar a questão da produção acadêmica na área de marketing. Mais do que isso, introduziu na academia norte-americana a noção de padrões de produtividade de pesquisa na carreira dos acadêmicos da área de marketing. Esse artigo, que serviu como uma primeira referência mais objetiva sobre a questão da produção acadêmica na área de marketing, teve suas preocupações ratificadas pelo trabalho de Bakir, Vitell e Rose (2000). 
No Brasil, questões relativas à produção acadêmica e temas de pesquisa na área de marketing foram inicialmente apresentadas e discutidas nos trabalhos de Vieira (1998, 1999, 2000). Esses trabalhos foram seguidos por outros que passaram a abordar modos e circunstâncias específicas no que se refere aos aspectos metodológicos da realização das pesquisas em marketing. Foram os casos, por exemplo, de Perin et al. (2000), que desenvolveram um estudo sobre o uso de pesquisas surveys em trabalhos publicados nos Anais do Enanpad, de Révillion (2001), que investigou a adoção de pesquisas de caráter exploratório na área de marketing, e de Botelho e Macera (2001), que analisaram as implicações decorrentes da falta de uma metateoria para a construção teórica em marketing.

O papel fundamental da produção acadêmica na área de marketing, assim como em qualquer outra área de conhecimento, é o de servir de referência para praticantes e estudiosos, no caso, de marketing. Isso é traduzido em várias instâncias que vão desde a origem e a formação de cada programa de pós-graduação e estudos em Administração, até a especialização, vocação e definição de linhas de pesquisa em cada um deles, bem como a agenda temática dos principais periódicos científicos de Administração do país. Compreende-se que a renovação e o vigor da produção acadêmica no âmbito de cada programa de pós-graduação e pesquisa em Administração, por exemplo, ocorram essencialmente pela própria produção e por aquilo que ela reflete na forma de publicação científica. À medida que se estabelece uma produção inicial, portanto, engendra-se a possibilidade de se constituir um fluxo onde a noção mais importante para o avanço do conhecimento é a de continuidade.

Ultrapassando as fronteiras de cada programa de pósgraduação e pesquisa, e reunindo a produção de todos eles, tem-se uma referência mais ampla, diversificada e representativa da produção acadêmica brasileira na área de marketing. Logo, a publicação presente nos periódicos, e que é originária dessa produção, constitui a síntese dos caminhos da pesquisa em marketing na academia brasileira.

A consequência natural desse processo é que a publicação contida nos principais periódicos científicos brasileiros de Administração serve como uma referência básica e mais imediata para todo e qualquer estudo de marketing realizado no âmbito da academia brasileira, desde que a temática estudada esteja contemplada por meio de trabalhos publicados. Considerando a amplitude temática do escopo desses periódicos ou, por outro lado, o caráter de síntese que apresentam em termos de produção acadêmica, tal situação configura-se no sentido de que os Anais do Enanpad, a RAUSP e a RAE evidenciem-se como as primeiras referências dentro do processo de retroalimentação da produção acadêmica de marketing no Brasil, particularmente nos anos 1990 .

\section{VENDO 0 ESPELHO: SOBRE O PROCEDIMENTO METODOLÓGICO}

Considerando o objetivo proposto, o procedimento metodológico seguido referiu-se à pesquisa bibliográfica, que utiliza, segundo Medeiros (1991), os passos convencionais da metodologia científica quanto ao controle de variáveis, observação de fatos e estabelecimento de leis ou checagem de conhecimentos adquiridos. Dessa forma, levou-se a efeito o trabalho de identificação, compilação e análise e interpretação das referências bibliográficas dos artigos publicados nos Anais do Enanpad, na RAUSP e na RAE, os quais foram considerados, conforme justificado anteriormente, os principais periódicos no que se refere à veiculação da produção científica na área de marketing no Brasil. Como horizonte cronológico da pesquisa, foi definido o período de 1990 a 1999, o que totalizou a análise de 272 artigos publicados ao longo de dez anos nesses periódicos.

Os artigos foram identificados como pertencentes à área de marketing por meio dos seguintes procedimentos: a) nos Anais do Enanpad, pelo fato de, até o ano de 1996, existir uma edição exclusiva dos Anais para a área de marketing, e, posteriormente, por existir uma seção específica para essa área tanto no livro de resumos dos trabalhos apresentados no encontro quanto no CD-ROM que acompanha tal livro; b) na RAUSP e na RAE, pelas seções temáticas contidas em ambas as revistas nos últimos anos e, anteriormente, por meio dos títulos, resumos dos artigos e, sobretudo, palavraschave.

O processo de coleta e análise de dados deu-se em função das seguintes variáveis: 1) ano de publicação do artigo; 2) temática de marketing do artigo; 3) número de autores por artigo; 4) filiação acadêmica dos autores; 5) número de citações - referências bibliográficas - por artigo; 6) número de citações de trabalhos publicados em periódicos; 7) número de citações de trabalhos publicados em periódicos internacionais; 8) número de citações de trabalhos publicados em perió- 
dicos brasileiros; 9) número de citações de trabalhos publicados na RAUSP; 10) número de citações de trabalhos publicados na RAE; e 11) número de citações de trabalhos publicados nos Anais do Enanpad. Essas variáveis foram escolhidas por permitirem, em seu conjunto, responder à questão feita para a investigação, quer seja, se o acadêmico brasileiro de marketing faz uso da produção brasileira de marketing como uma referência para as pesquisas e estudos que realiza. Os dados coletados na pesquisa foram tabulados e tratados estatisticamente por meio do uso do software Le Sphinx Plus $^{\circledR}$, versão 1.32 .

\section{AS IMAGENS DO ESPELHO: A PUBLICAÇÃO CIENTÍFICA NA ÁREA DE MARKETING NO BRASIL}

Um total de 272 artigos de marketing - trabalhos resultantes de pesquisas teóricas, empíricas, ensaios etc. - foram publicados no Brasil de 1990 a 1999 (Quadro 1). As principais temáticas estudadas foram comportamento do consumidor (18,8\%), serviços $(10,3 \%)$ e estratégias de mercado $(9,9 \%)$. Houve, portanto, um nítido direcionamento dos estudos e pesquisas no sentido de se conhecer melhor o mercado consumidor brasileiro. O fato de a temática de serviços ser a segunda mais estudada, reforça a percepção de uma preocupação crescente com o mercado e de uma tentativa de ampliar e melhorar a relação com o mesmo. Indica, também, que a academia refletiu de modo direto um movimento que ocorreu na economia como um todo durante a última década, cujos principais pontos de envolvimento para a área de marketing relacionaramse ao Código de Defesa do Consumidor, à abertura da economia com o aumento das importações de bens duráveis e não duráveis, e ao movimento pela Qualidade Total, incluindo-se aí a ampliação da escala de prestação de serviços ao consumidor na economia brasileira de um modo geral.

É importante observar que vários estudos também foram publicados sobre aspectos multidisciplinares $e$ pluralísticos de marketing (10,7\%), que não é uma categoria tradicional de estudos de marketing. Essa categoria foi adotada para traduzir, no âmbito deste artigo, o conjunto dos trabalhos cuja temática envolveu a abordagem de questões relativas a outras áreas de conhecimento, entretanto complementares à administração de marketing, como, por exemplo, Estatística, Educação e Antropologia. De certa forma, tal volume de artigos implica a existência de um diálogo constante do marke- ting com outras áreas de conhecimento que trazem relevantes contribuições para análise e entendimento de sua prática. Fruto de estudos desenvolvidos, em geral, no âmbito de programas de pós-graduação e pesquisa em Administração, esses artigos revelam também, de alguma maneira, uma certa dependência do conhecimento oriundo de outras áreas para a construção e consolidação de um estatuto teórico que lhe seja particular.

De modo complementar, novos paradigmas e modelos conceituais e teóricos $(6,3 \%)$ concernem a trabalhos que apresentam modelos diferenciados e novas propostas de abordagem ao marketing convencional. Outros $(8,5 \%)$ dizem respeito a temáticas gerais de marketing, como marketing de defesa, marketing de tecnologia, marketing social, automação bancária, webmarketing, Internet, entre outras. A observação de uma menor quantidade de tais itens do Quadro 1 nas publicações vinculadas à RAUSP e à RAE deve-se ao fato de elas serem bem mais definidas do que as dos Anais do Enanpad. Talvez, por se tratar de uma publicação vinculada a um congresso, os artigos dos Anais tenham temas mais amplos e explorem temáticas não convencionais ou não tradicionais de marketing.

Dos artigos publicados, $44,1 \%$ são escritos por um autor, $40,1 \%$ por dois autores, $14 \%$ por três, e 1,8 \% por quatro ou mais autores (Quadro 2). Observa-se que, embora a incidência de trabalhos escritos por dois ou mais autores seja significativa, ela apresenta atenuantes à sua importância inicial. Por um lado, ela está restrita a autores de uma mesma instituição, o que tanto pode implicar um aspecto positivo de constante trabalho em equipe, interatividade, reflexão conjunta e / ou grupos de pesquisa, como pode ser um aspecto negativo, de forte processo de endogenia, ausência de intercâmbio acadêmico e institucional. Por outro lado, e em sua maior parte, ela está vinculada originalmente a trabalhos orientados, nos quais se explicita uma relação professor-aluno, com o professor assumindo o papel de co-autor. Além disso, observa-se uma vinculação a trabalhos que são frutos de disciplinas de cursos de mestrado e / ou doutorado, envolvendo a parceria de dois ou mais alunos e / ou professores.

As instituições que têm tido maior participação em termos de filiação acadêmica dos autores dos artigos publicados são, respectivamente, de primeiro a quinto lugar: UFRGS, USP, UFRJ, FGV-EAESP e PUC-RJ (Quadro 3). Os autores filiados à UFRGS estão mais presentes nas publicações dos Anais do Enanpad (26,6\%) e na RAUSP (16,7\%). Aqueles filiados à USP e à PUC-RJ são os únicos, entre as cinco instituições com maior publi- 
cação, que estão presentes em todos os periódicos. Os autores vinculados à UFRJ concentram sua publicação nos Anais do Enanpad (13,3\%). Os filiados à FGV-EAESP concentraram mais de $75 \%$ de sua produção na revista editada pela própria instituição.
Uma observação pertinente é a de que, sob a ótica da delimitação de áreas de competência dos programas de pós-graduação filiados à Anpad, a distribuição da filiação acadêmica dos autores dos artigos publicados assinala a importância e a amplitude da presença da área de marke-

Quadro 1 - Temática dos artigos de marketing publicados no Brasil

\begin{tabular}{|c|c|c|c|c|c|c|c|c|}
\hline \multirow{3}{*}{ TEMÁTICA } & \multicolumn{6}{|c|}{ PERIÓDICOS } & \multirow{2}{*}{\multicolumn{2}{|c|}{ TOTAL }} \\
\hline & \multicolumn{2}{|c|}{ ANAIS ENANPAD } & \multicolumn{2}{|c|}{ RAUSP } & \multicolumn{2}{|c|}{ RAE } & & \\
\hline & N & $\%$ & $\mathrm{~N}$ & $\%$ & $\mathrm{~N}$ & $\%$ & N & $\%$ \\
\hline Atacado e varejo & 6 & 2,8 & 2 & 11,1 & 2 & 5,5 & 10 & 3,7 \\
\hline Comportamento do consumidor & 43 & 19,7 & 6 & 33,3 & 2 & 5,5 & 51 & 18,8 \\
\hline Comunicação e propaganda & 11 & 5 & 1 & 5,6 & 4 & 11,1 & 16 & 5,9 \\
\hline Databasemarketing & 1 & 0,5 & 0 & 0 & 4 & 11,1 & 5 & 1,8 \\
\hline Definição de preço & 4 & 1,8 & 0 & 0 & 2 & 5,5 & 6 & 2,2 \\
\hline Distribuição e logística & 8 & 3,7 & 1 & 5,6 & 2 & 5,5 & 11 & 4 \\
\hline Estratégias de mercado & 22 & 10,1 & 1 & 5,6 & 4 & 11,1 & 27 & 9,9 \\
\hline Integração e comércio internacional & 2 & 0,9 & 0 & 0 & 0 & 0 & 2 & 0,7 \\
\hline Posicionamento e marcas de produtos & 7 & 3,2 & 0 & 0 & 0 & 0 & 7 & 2,6 \\
\hline Potencial e participação de mercado & 0 & 0 & 0 & 0 & 2 & 5,5 & 2 & $\mathbf{0 , 7}$ \\
\hline Qualid. e desenv. de produtos & 7 & 3,2 & 1 & 5,6 & 2 & 5,5 & 10 & 3,7 \\
\hline Segmentação e nichos de mercado & 8 & 3,7 & 1 & 5,6 & 1 & 2,8 & 10 & 3,7 \\
\hline Serviços & 24 & 11 & 1 & 5,6 & 3 & 8,3 & 28 & 10,3 \\
\hline Aspect. multidiscip. e plural. de marketing & 24 & 11 & 0 & 0 & 5 & 13,8 & 29 & 10,7 \\
\hline Ambientes e sistemas de marketing & 1 & 0,5 & 0 & 0 & 1 & 2,8 & 2 & 0,7 \\
\hline Sistemas de informação e pesquisa & 13 & 6 & 3 & 16,6 & 0 & 0 & 16 & 5,9 \\
\hline Novos paradigmas, model. conc. e teóricos & 16 & 7,3 & 1 & 5,6 & 0 & 0 & 17 & 6,3 \\
\hline Outros & 21 & 9,6 & 0 & 0 & 2 & 5,5 & 23 & 8,5 \\
\hline Total & 218 & 100 & 18 & 100 & 36 & 100 & 272 & 100 \\
\hline
\end{tabular}

Fonte: Pesquisa bibliográfica, Anais do Enanpad, RAUSP, RAE (1990-99).

Quadro 2 - Número de autores por artigo de marketing publicado no Brasil

\begin{tabular}{|c|c|c|c|c|c|c|c|c|}
\hline \multirow{3}{*}{$\begin{array}{l}\text { NÚMERO DE AUTORES } \\
\text { POR TRABALHO }\end{array}$} & \multicolumn{6}{|c|}{ PERIÓDICOS } & \multicolumn{2}{|c|}{ TOTAL } \\
\hline & \multicolumn{2}{|c|}{ ANAIS ENANPAD } & \multicolumn{2}{|c|}{ RAUSP } & \multicolumn{2}{|c|}{ RAE } & & \\
\hline & $\mathrm{N}$ & $\%$ & $\mathrm{~N}$ & $\%$ & $\mathrm{~N}$ & $\%$ & $\mathrm{~N}$ & $\%$ \\
\hline Trabalhos com 1 autor & 94 & 43,1 & 6 & 33,3 & 20 & 55,6 & 120 & 44,1 \\
\hline Trabalhos com 2 autores & 91 & 41,7 & 6 & 33,3 & 12 & 33,3 & 109 & 40,1 \\
\hline Trabalhos com 3 autores & 28 & 12,8 & 6 & 33,3 & 4 & 11,1 & 38 & 14 \\
\hline Trabalhos com 4 ou mais autores & 5 & 2,3 & - & - & - & - & 5 & 1,8 \\
\hline Total & 218 & 100 & 18 & 100 & 36 & 100 & 272 & 100 \\
\hline
\end{tabular}

Fonte: Pesquisa bibliográfica, Anais do Enanpad, RAUSP, RAE (1990-99). 
ting nesses programas, o que pode revelar parte da competência e excelência de cada um deles dentro do contexto da Administração no Brasil. É possível, assim, que, em função da significativa produção na área de marketing que apresentam, eles venham a ser procurados por estudantes e/ou docentes em processos de qualificação interessados no desenvolvimento de estudos e pesquisas na área de marketing.

A publicação científica na área de marketing está mais alicerçada em referências bibliográficas oriundas de periódicos do que de livros (Quadro 4). A diferença entre o uso de periódicos e livros, entretanto, é pequena. Com uma média de 11,2 referências de periódicos contra 10,4 referências de livros, os artigos publicados na área de marketing no Brasil evidenciam forte tendência a usar informações consagradas em manuais e best sellers que, se por um lado podem servir como orientação teórica geral, por outro podem estar desatualizadas e carentes de comprovação e novos testes empíricos diante de distintos cenários de marketing. De certo modo, esse comportamento acadêmico de se recorrer a best sellers como fonte preferencial para pesquisa acadêmica sugere alguma vinculação com procedimentos didático-pedagógicos dos professores dos programas de pós-graduação, sobretudo se for levado em consideração que parte significativa da publicação tem estudantes de pós-graduação como seus responsáveis. Além disso, existe também a possibilidade de uma associação com o trabalho de divulgação e promoção por parte das empresas presentes no mercado editorial brasileiro, as quais, via de regra, são transnacionais e reproduzem uma lógica em seus trabalhos de divulgação semelhante àquelas de seus países de origem, cujos autores são renomados acadêmicos de grandes escolas internacionais de business que, de uma forma ou de outra, ten-

Quadro 3 - Filiação acadêmica dos autores dos artigos de marketing publicados no Brasil, segundo instituição de origem do primeiro autor e quantidade de artigos

\begin{tabular}{|c|c|c|c|c|c|c|c|c|}
\hline \multirow{3}{*}{ FILIAÇÃO DOS AUTORES } & \multicolumn{6}{|c|}{ PERIÓDICOS } & \multicolumn{2}{|c|}{ TOTAL } \\
\hline & \multicolumn{2}{|c|}{ ANAIS ENANPAD } & \multicolumn{2}{|c|}{ RAUSP } & \multicolumn{2}{|c|}{ RAE } & & \\
\hline & $\mathrm{N}$ & $\%$ & $\mathrm{~N}$ & $\%$ & $\mathrm{~N}$ & $\%$ & $\mathrm{~N}$ & $\%$ \\
\hline FGV-EAESP & 6 & 2,8 & - & - & 21 & 58,3 & 27 & 9,9 \\
\hline PUC-RJ & 14 & 6,4 & 1 & 5,6 & 3 & 8,3 & 18 & 6,6 \\
\hline UFBA & 1 & 0,5 & - & - & - & - & 1 & 0,4 \\
\hline UFMG & 9 & 4,1 & 1 & 5,6 & 1 & 2,8 & 11 & 4 \\
\hline UFPB & 5 & 2,3 & - & - & - & - & 5 & 1,8 \\
\hline UFPE & 10 & 4,6 & - & - & - & - & 10 & 3,7 \\
\hline UFPR & 9 & 4,1 & 1 & 5,6 & - & - & 10 & 3,7 \\
\hline UFRGS & 58 & 26,6 & 3 & 16,7 & - & - & 61 & 22,4 \\
\hline UFRJ & 29 & 13,3 & - & - & - & - & 29 & 10,7 \\
\hline UFRN & 2 & 0,9 & - & - & 1 & 2,8 & 3 & 1,1 \\
\hline UFSC & 2 & 0,9 & - & - & - & - & 2 & 0,7 \\
\hline USP & 27 & 12,4 & 6 & 33,3 & 2 & 5,6 & 35 & 12,9 \\
\hline Outras Inst. de Ensino Sup. Nacionais - Públicas & 12 & 5,5 & 1 & 5,6 & 4 & 11,1 & 17 & 6,3 \\
\hline Outras Inst. de Ensino Sup. Nacionais - Privadas & 20 & 9,2 & 4 & 22,2 & 1 & 2,8 & 25 & 9,2 \\
\hline Outras Inst. de Ensino Sup. Internac. - EUA & 1 & 0,5 & - & - & 2 & 5,6 & 3 & 1,1 \\
\hline Outras Inst. de Ensino Sup. Internac. - Europa & 8 & 3,7 & - & - & - & - & 8 & 2,9 \\
\hline Outras Inst. de Ensino Sup. Internac.- América Latina & 2 & 0,9 & - & - & - & - & 2 & 0,7 \\
\hline Executivos & 3 & 1,4 & 1 & 5,6 & 1 & 2,8 & 5 & 1,8 \\
\hline Total & 218 & 100 & 18 & 100 & 36 & 100 & 272 & 100 \\
\hline
\end{tabular}

Fonte: Pesquisa bibliográfica, Anais do Enanpad, RAUSP, RAE (1990-99). 
dem a amalgamar o conhecimento de marketing management por meio de textos prescritivos que servem tanto para os Estados Unidos ou a França, quanto para o Brasil ou a Indonésia.

Embora tenha aumentado o número médio de citações de periódicos por artigo publicado, o grande uso de referências de livros revela também um distanciamento teórico da fronteira do conhecimento por parte da produção acadêmica publicada na área de marketing. Como elemento de partida conceitual, teórico e metodológico, o conteúdo dos periódicos, sobretudo os científicos, são mais relevantes que aqueles dos livros, pois apresentam maior diversidade de situações, refinamento teórico, modelos de análise e dados primários e / ou secundários de realidades empíricas da prática empresarial em administração de marketing. Por princípio, ao se fazer pesquisa acadêmica, os mesmos deveriam ser priorizados em lugar de best sellers.

Esse cenário é típico da academia brasileira se comparado a outras academias, como a inglesa e a norteamericana, por exemplo. Ele não se explica no âmbito das instituições de origem dos autores dos artigos, pois, em geral, os programas de pós-graduação aos quais estão filiados, e que via de regra fazem parte da Anpad, apresentam bibliotecas com condições para o acesso de periódicos, serviços de "comut", bases de dados e anais de congressos e encontros realizados no Brasil e / ou no exterior. Não por acaso é que, a título de ilustração, os artigos de origem estrangeira publicados no Brasil (Quadro 3) são aqueles que apresentam os maiores números de referências de periódicos como forma de embasamento e discussão do conteúdo abordado em suas páginas.

Por sua vez, do ponto de vista da utilização de periódicos como referências, os artigos publicados evidenciam principalmente periódicos de origem internacional, os quais são predominantemente norte-americanos. A média de utilização de referências de periódicos brasileiros é de apenas 2,0 contra 9,1 de periódicos internacionais por artigo publicado. Essa média é ainda mais ínfima, do ponto de vista acadêmico, se for observado que os três principais periódicos brasileiros de administração, juntos, têm uma média de apenas 0,6 referências por artigo publicado. Em ordem de maior incidência de ci-

Quadro 4 - Número de artigos publicados, número e média de referências

bibliográficas, número e média de referências de periódicos - total, internacionais, brasileiros, ${ }^{(1)}$

\begin{tabular}{|c|c|c|c|c|c|c|c|c|c|c|c|c|c|c|c|c|}
\hline \multirow[t]{2}{*}{ ANO } & \multicolumn{2}{|c|}{$\begin{array}{c}\text { ARTIGOS DA } \\
\text { RAUSP, RAE E } \\
\text { ANAIS DO } \\
\text { ENANPAD }\end{array}$} & \multicolumn{2}{|c|}{ REFERÊNCIAS } & \multicolumn{2}{|c|}{$\begin{array}{c}\text { REF. DE } \\
\text { PERIÓDICOS }\end{array}$} & \multicolumn{2}{|c|}{$\begin{array}{c}\text { REF. DE } \\
\text { PERIÓDICOS } \\
\text { INTERNA- } \\
\text { CIONAIS }\end{array}$} & \multicolumn{2}{|c|}{$\begin{array}{c}\text { REF. DE } \\
\text { PERIÓDICOS } \\
\text { BRASILEIROS }\end{array}$} & \multicolumn{2}{|c|}{$\begin{array}{l}\text { REF. DOS } \\
\text { ANAIS DO } \\
\text { ENANPAD }\end{array}$} & \multicolumn{2}{|c|}{$\begin{array}{c}\text { REF. } \\
\text { DA RAUSP }\end{array}$} & \multicolumn{2}{|c|}{$\begin{array}{c}\text { REF. } \\
\text { DA RAE }\end{array}$} \\
\hline & N & $\%$ & N & $\bar{x}$ & N & $\bar{x}$ & $\mathrm{~N}$ & $\bar{x}$ & N & $\bar{x}$ & N & $\bar{x}$ & $\mathrm{~N}$ & $\bar{x}$ & N & $\bar{x}$ \\
\hline 1990 & 18 & 100 & 189 & 10,5 & 69 & 3,8 & 43 & 2,4 & 26 & 1,4 & 4 & 0,2 & 4 & 0,2 & - & - \\
\hline 1991 & 22 & 100 & 261 & 11,9 & 97 & 4,4 & 71 & 3,2 & 26 & 1,2 & 2 & 0,1 & 5 & 0,2 & - & . \\
\hline 1992 & 16 & 100 & 255 & 15,9 & 129 & 8,1 & 100 & 6,2 & 29 & 1,8 & - & - & 6 & 0,4 & 2 & 0,1 \\
\hline 1993 & 22 & 100 & 530 & 24,1 & 286 & 13 & 224 & 10,2 & 62 & 2,8 & 2 & 0,1 & 6 & 0,3 & 3 & 0,1 \\
\hline 1994 & 25 & 100 & 688 & 27,5 & 339 & 13,6 & 277 & 11,1 & 62 & 2,5 & 2 & 0,1 & 4 & 0,2 & 5 & 0,2 \\
\hline 1995 & 27 & 100 & 564 & 20,1 & 304 & 11,2 & 263 & 9,7 & 41 & 1,5 & 2 & 0,1 & 2 & 0,1 & 4 & 0,1 \\
\hline 1996 & 36 & 100 & 819 & 22,7 & 470 & 13 & 381 & 10,6 & 59 & 1,6 & 6 & 0,2 & 4 & 0,1 & 3 & 0,1 \\
\hline 1997 & 35 & 100 & 665 & 19 & 303 & 8,6 & 213 & 6,1 & 86 & 2,4 & 9 & 0,3 & 7 & 0,2 & 6 & 0,2 \\
\hline 1998 & 37 & 100 & 974 & 26,3 & 538 & 14,5 & 434 & 11,7 & 100 & 2,7 & 28 & 0,7 & 2 & 0,1 & 4 & 0,1 \\
\hline 1999 & 34 & 100 & 938 & 27,6 & 519 & 15,3 & 471 & 13,8 & 48 & 1,4 & 27 & 0,8 & 2 & 0,1 & 2 & 0,1 \\
\hline TOTAL & 272 & 100 & 5883 & 21,6 & 3054 & 11,2 & 2477 & 9,1 & 539 & 2,0 & 82 & 0,3 & 42 & 0,2 & 29 & 0,1 \\
\hline
\end{tabular}

Fonte: Pesquisa bibliográfica, Revista de Administração de Empresas (1990-99).

(1) Originalmente, os dados oriundos dessas variáveis, transformadas em questões abertas e numéricas, foram agrupados em classes de igual amplitude no processo de tratamento e análise de dados do Le Sphinx Plus ${ }^{\circledR}$. Para efeitos de apresentação, decidiu-se suprimir uma casa decimal, o que pode levar, eventualmente, a pequenas diferenças de totalização. 
tação, os Anais do Enanpad têm uma média de 0,3 por artigo publicado, a RAUSP tem uma média de 0,2 e a RAE tem uma média de 0,1 referência por artigo. As outras 1,4 referências brasileiras, em média, por artigo publicado, são relativas a periódicos não científicos, como Folha de S. Paulo, Gazeta Mercantil, Zero Hora, Veja, Exame e outras do tipo setorial, ou periódicos científicos brasileiros de outras áreas interdisciplinares à Administração.

O uso e a citação de referências de periódicos brasileiros envolvem um curioso aspecto que merece atenção: em 255 referências de periódicos ao longo de dez anos de publicação por parte da RAUSP, não há uma única referência - citação - da RAE. Por sua vez, no âmbito da RAE, em um total de 263 referências de periódicos em uma década em que foram publicados 36 artigos de marketing, há uma única citação de um artigo publicado na RAUSP.

A distância entre a média de 9,1 referências de periódicos internacionais contra 2,0 referências de periódicos brasileiros por artigo, sugere que o acadêmico brasileiro tem o olhar voltado para fora. Embora faça pesquisa na realidade objetiva e mais imediata brasileira, o pesquisador de marketing usa predominantemente a referência teórica internacional na construção de seu quadro teórico e metodológico de análise. Assim, pesquisa-se uma determinada realidade empírica e usa-se o referencial teórico-metodológico de uma outra como instrumento de análise e explicação.

Proceder dessa forma não é de todo impossível ou impraticável do ponto de vista científico. Determinadas realidades empíricas empresariais e de situações de marketing são por demais semelhantes, o que permite usar referências externas com grande contribuição de análise e explicação. Não é o caso de se estabelecer uma reserva de mercado científica. Pensar assim seria retroceder nos pressupostos que movem a produção do conhecimento e adentrar uma discussão que oferece elementos para longos e passionais debates, como ilustram os ensaios de Bloom (1989), Jacoby (1990) e Kourganoff (1990). O que, a rigor, caracteriza-se como inexplicável, pelo menos em um primeiro momento, é a quase não utilização de referências da própria produção acadêmica brasileira em marketing.

Considerando-se que a realidade que se investiga, cujos resultados são publicados na forma de artigo científico nos periódicos, é a brasileira, e considerando-se que existe uma significativa produção acadêmica veiculada nesses periódicos, não existe uma explicação objetiva para se prescindir tanto dessa produção aca- dêmica se não a caracterizar como se fosse algo impróprio para si mesma. A análise dos 272 artigos publicados ao longo de dez anos assinala a existência da continuidade temática, como já foi mencionado em momento anterior. Todavia, isso não tem sido suficiente para que os artigos que são publicados seqüencialmente façam uso de referências temáticas anteriores da mesma instância e fórum a que se submetem à apresentação e publicação.

\section{NARCISO SEM ESPELHO: SOBRE AS CONCLUSÕES E IMPLICAÇÕES TEÓRICO-ACADÊMICAS}

A análise da publicação científica na área de marketing no Brasil, considerando os Anais do Enanpad, a RAUSP e a RAE, permite algumas conclusões:

a) a pesquisa em marketing no Brasil tem se voltado para os temas de comportamento do consumidor, marketing de serviços (incluindo aspectos de desenvolvimento, qualidade e atendimento), estratégias de mercado, comunicação e propaganda e sistemas de informação e pesquisa em marketing;

b) as instituições que têm a maior produção acadêmica na área de marketing no Brasil, no âmbito da publicação dos principais periódicos de administração brasileiros, são a UFRGS, a USP, a UFRJ, a FGV-EAESP e a PUC-RJ;

c) o acadêmico brasileiro de marketing usa uma larga proporção de livros, em relação a periódicos, como fontes de referência para a construção do quadro teórico-metodológico de suas análises e investigações científicas;

d) quando usa periódicos como referências em seus estudos, o pesquisador brasileiro de marketing privilegia os periódicos internacionais; e

e) existe uma descontinuidade e fragilidade da pesquisa e da produção acadêmica em marketing no Brasil porque, embora essa produção apresente consideráveis referências sobre a realidade empírica empresarial brasileira, os pesquisadores de marketing no Brasil têm relegado tais referências - publicações - como fontes de pesquisa.

Diante desse quadro, portanto, percebe-se que o olhar do pesquisador brasileiro de marketing está voltado para os outros de além-mar. Esse tipo de comportamento desencadeia um processo em que há poucas citações de seus próprios trabalhos, fazendo com que o pesquisador não se veja na produção de seu próprio país. Na mitologia grega, Narciso morreu porque se apaixonou por sua própria beleza e ficou parado à bei- 
ra de uma fonte, admirando-se dias e dias até seu corpo definhar por falta de alimento. Se tomada de modo linear, essa passagem da mitologia grega daria a entender que o acadêmico brasileiro de marketing também definharia se ficasse restrito apenas à própria produção, repetindo-se e caindo na armadilha da endogenia. Entretanto, o oposto também traz um significado, ou seja, ao insistir em olhar para os outros e para fora, o acadêmico brasileiro de marketing distancia-se de sua própria realidade e, com isso, compromete suas próprias pesquisas e não estimula a continuidade do conhecimento que produz. Tendo em vista os resultados da pesquisa aqui apresentada, trabalhar com referências externas, como já vem fazendo, e ao mesmo tempo adotar a produção de conhecimento local como um ponto de partida para suas pesquisas é o que parece ser o mais adequado para o pesquisador brasileiro da área de marketing.

Com efeito, há um estoque considerável de informações na área de marketing no Brasil. Desde o começo dos anos 1950, quando se iniciou o ensino dessa disciplina no Brasil, como lembra Richers (1994), muitas informações empíricas foram disponibilizadas e referenciais teóricos consideráveis foram desenvolvidos por pesquisadores brasileiros. Por que esse estoque de informação e conhecimento é tão pouco usado e às vezes preterido? Qual o sentido de se fazer pesquisas em marketing se elas não servirão como referências para estudos posteriores? Por que o acadêmico brasileiro que estuda comportamento do consumidor, por exemplo, menciona oito ou 12 pesquisas conduzidas fora do país, mas não cita aquelas quatro que, em passado recente, foram publicadas nos principais periódicos brasileiros por acadêmicos brasileiros? Essas perguntas saltam aos olhos por meio da observação dos resultados da pesquisa aqui apresentada. Embora seja razoável supor quais respostas deveriam ser oferecidas para as mesmas, não é possível respondê-las objetivamente, e isso representa alguns limites para este artigo.

Não obstante, aspectos relacionados à continuidade de linhas de pesquisa e continuidade temática de estudos de marketing no âmbito da produção acadêmica brasileira merecem futuras considerações perante os resultados aqui apresentados. Recursos financeiros direcionados a esforços de pesquisa em marketing também merecem consideração quanto à prioridade de alocação que podem ter ao se refletir sobre os resultados deste estudo. Tais questões podem ser contempladas pela comunidade relativa aos professores e coordenadores dos cursos de pós-graduação em Administração, pelos revisores e editores de periódicos científicos e pelas agências governamentais de fomento à pesquisa acadêmica e científica.

Artigo recebido em 17/01/2002. Aprovado em 13/04/2002.

\section{Notas}

O autor agradece aos professores Ricardo Leal, pelos comentários e incentivo à redação deste artigo, e Alexandre Faria, pelas observações críticas e sugestões à primeira versão. Limites ou eventuais falhas no texto, entretanto, são de responsabilidade exclusiva do próprio autor.

\section{Referências bibliográficas}

BAKIR, Aysen, VITELL, Scott J., ROSE, Gregory M. Publications in major marketing journals: an analysis of scholars and marketing departments. Journal of Marketing Education, v. 22, n. 2, p. 99-107, Aug. 2000

BERTERO, Carlos O., KEINERT, Tânia M. M. A evolução da análise organizacional no Brasil (1961-93). RAE - Revista de Administração de Empresas, São Paulo, v. 34, n. 3, p. 81-90, Mai./Jun. 1994.

BERTERO, Carlos O., CALDAS, Miguel P., WOOD JR., Thomaz. Produção científica em administração de empresas: provocações, insinuações e contribuições para um debate local. In: $22^{\circ}$ ENCONTRO ANUAL DA ASSOCIAÇÃO NACIONAL DOS PROGRAMAS DE PÓS-GRADUAÇÃO EM ADMINISTRAÇÃO, Foz do Iguaçu. Anais... Foz do Iguaçu: Anpad, 1998 Organizações.

BLOOM, Allan D. O declinio da cultura ocidental: da crise da universidade à crise da sociedade. São Paulo : Best Seller, 1989

BOTELHO, Delane, MACERA, Andrea. Análise metateórica de teses e dissertações da área de marketing apresentadas na FGV-EAESP (1974-1999). In: $25^{\circ}$ ENCONTRO ANUAL DA ASSOCIAÇÃO NACIONAL DOS PROGRAMAS DE PÓS-GRADUAÇÃO EM ADMINISTRAÇÃO, Campinas. Anais... Campinas: Anpad, 2001. Marketing.

BURNETT, John J., AMASON, Robert D., CUNNINGHAM, Peggy. What makes marketing academicians successful? An assessment of teaching, publishing and service. Journal of Marketing Education, v. 11, n. 3, p. 7-18, Set. 1989.

CHANLAT, Jean-François. Francophone organizational analysis (19501990): an overview. Organization Studies, Cambridge, v. 15, n. 1, p. 47-80, 1994.

JACOBY, Russell. Os últimos intelectuais: a cultura americana na era da academia. São Paulo : Trajetória Cultural / Editora da USP, 1990.

KOURGANOFF, Wladimir. A face oculta da universidade. São Paulo : Editora da Unesp, 1990. 
MACHADO DA SILVA, Clóvis L., CUNHA, Vera C., AMBONI, Nério. Organizações: o estado da arte da produção acadêmica no Brasil. In: 14으 ENCONTRO ANUAL DA ASSOCIAÇÃO NACIONAL DOS PROGRAMAS DE PÓS-GRADUAÇÃO EM ADMINISTRAÇÃO, 1990. Florianópolis. Anais... Florianópolis: Anpad, 1990. Organizações.

MEDEIROS, João B. Redação científica: a prática de fichamentos, resumos, resenhas. São Paulo : Atlas, 1991. 144p.

NIEMI JR., Albert. W. Publication performance of marketing departments, 1975-1985. Journal of Marketing Education, v. 10, n. 2, p. 8-12, May 1988.

PERIN, Marcelo G., SAMPAIO, Cláudio H., FROEMMING, Lurdes M. S., LUCE, Fernando B. A pesquisa survey em artigos de marketing nos Enanpads da década de 90. In: 22o ENCONTRO ANUAL DA ASSOCIAÇÃO NACIONAL DOS PROGRAMAS DE PÓS-GRADUAÇÃO EM ADMINISTRAÇÃO, Foz do Iguaçu. Anais... Foz do Iguaçu : Anpad, 1998. Marketing.

POWERS, Thomas L., SWAN, John E., PATTON, John F. Career research productivity patterns of marketing academicians. Journal of Business Research, New York, v. 42, n. 1, p. 75-86, 1998.

RÉVILLION, Anya S. P. A utilização de pesquisas exploratórias na área de marketing. In: 25 ENCONTRO ANUAL DA ASSOCIAÇÃO NACIONAL DOS PROGRAMAS DE PÓS-GRADUAÇÃO EM ADMINISTRAÇÃO, 2001. Campinas. Anais... Campinas : Anpad, 2001. Marketing.

RICHERS, Raimar. Recordando a infância do marketing brasileiro - um depoimento. RAE - Revista de Administração de Empresas, São Paulo, v. 34, n. 3, p. 26-40, Mai.Jun. 1994.
SHERRELL, Daniel L., HAIR JR., Joseph F, GRIFFIN, Mitch. Marketing academicians' perceptions of ethical research and publishing behavior. Journal of The Academy of Marketing Science, Greenvale, v. 17, n. 4, p. $315-$ 24, Set. 1989.

VERGARA, Sylvia C., CARVALHO JR., Dourival de S. Nacionalidade dos autores referenciados na literatura brasileira sobre organizações. In: ENCONTRO ANUAL DA ASSOCIAÇÃO NACIONAL DOS PROGRAMAS DE PÓS-GRADUAÇÃO EM ADMINISTRAÇÃO, 19º , 1995, João Pessoa. Anais... João Pessoa: Anpad, 1995. Vol. 6. Organizações. p. 169-88.

VIEIRA, Francisco G. D. Por quem os sinos dobram? Uma análise da publicação científica na área de marketing do Enanpad. In: ENCONTRO ANUAL DA ASSOCIAÇÃO NACIONAL DOS PROGRAMAS DE PÓS-GRADUAÇÃO EM ADMINISTRAÇÃO, 22ํㅜ, 1998, Foz do Iguaçu. Anais... Foz do Iguaçu: Anpad, 1998. Marketing.

VIEIRA, Francisco G. D. Ações empresariais e prioridades de pesquisa em marketing: tendências no Brasil e no mundo segundo a percepção dos acadêmicos brasileiros. In: 23ํㅡㄹ ENCONTRO ANUAL DA ASSOCIAÇÃO NACIONAL DOS PROGRAMAS DE PÓS-GRADUAÇÃO EM ADMINISTRAÇÃO, 1999, Foz do Iguaçu. Anais... Foz do Iguaçu: Anpad, 1999. Marketing.

VIEIRA, Francisco G. D. Panorama acadêmico-científico e temáticas de estudos de marketing no Brasil. In: 24 NCONTRO ANUAL DA ASSOCIAÇÃO NACIONAL DOS PROGRAMAS DE PÓS-GRADUAÇÃO EM ADMINISTRAÇÃO, 2000, Florianópolis. Anais... Florianópolis : Anpad, 2000. Marketing

\author{
Francisco Giovanni D. Vieira \\ Professor-Adjunto de Marketing da UEM e Co-Editor da RIMAR - Revista Interdisciplinar \\ de Marketing. Doutor em Ciências Sociais pela PUC-SP e Mestre em Administração pela \\ UFLA. Interesses de pesquisa em Educação e Ensino em Marketing, Comportamento do \\ Consumidor, Marketing Social e Cultura nas Organizações. \\ E-mail: fgdvieira@uem.br \\ Endereço: UEM - DAD. Av. Colombo, 5790 - Zona 7, 87020-900, Maringá - PR.
}

